\title{
Diferencias individuales en cognición: una nueva aproximación a la inteligencia *
}

\author{
C. HUNT \\ N. FROST \\ C. LUNNEBORG
}

$\bigodot_{\varphi}$

(*) Original: Individual differences in cognition: A New Approach to Intelligence. En C. Bower (Ecomp.): Advances in Learning and Motivation, vol. 7. Nueva York: Academic Press, 1973. Traducido por R. Colom Marañón, Facultad de Psicología de la Universidad Autónoma de Madrid. 


\section{4}

\section{INTRODUCCIÓN}

El hecho de las diferencias individuales en el funcionamiento mental es una realidad que no debe dudarse. Su amplitud y naturaleza tiene unas consecuencias tan importantes en nuestra cultura tecnológicamente orientada que hace que la sociedad demande una forma de medir la inteligencia. Los psicólogos han respondido a esta demanda con tests que fuesen una contribución sustancial a la tecnología. No obstante, según algunos psicólogos, los tests de inteligencia son un instrumento de medida que no representa adecuadamente un determinado modelo formal de la dinámica de los procesos de pensamiento. Este artículo consiste en una serie de argumentos teóricos y empíricos contra la separación de los tests y las teorías cognitivas. Creemos que pueden producirse sustanciales beneficios del acercamiento entre el psicólogo experimental y el psicómetra; los datos disponibles nos indican cómo se puede producir este acercamiento.

Antes de presentar nuestro argumento, procederemos a realizar un breve repaso histórico. ¿Cómo es posible que una ciencia adicta a la Lógica de la Ciencia haya desarrollado una tecnología ateórica? La respuesta parece estar en la insistencia pública para desarrollar aplicaciones socialmente relevantes con preferencia a cualquier desarrollo teórico. El primer científico moderno que estudió las diferencias individuales fue Francis Galton, hace unos cien años. Galton desarrolló una teoría de la cognición. Pensaba que la inteligencia era, en parte, un rasgo general y heredable de «capacidad para la supervivencia». Además, Galton fue un buen científico; su teoría se desarrolló de acuerdo a observaciones directas. Puesto que esa «capacidad» tenía componentes físicos y mentales, Galton supuso que, tanto la rapidez de golpear de un saco como la rapidez de cálculo aritmético, eran indicadores válidos de la presencia o ausencia de genio. Desde el punto de vista actual, sabemos que la teoría de Galton era errónea. Sus mediciones del funcionamiento motor cognitivo se difuminaban por las mediciones del funcionamiento. Por tanto, los tests de Galton no tuvieron éxito a la hora de identificar lo que pretendían. Por ejemplo, sus tests no distinguían los miembros de la Royal Society del resto de la población londinense. De hecho, Galton acabó admitiendo que sus medidas de la capacidad casi no tenían utilidad práctica.

La aproximación científica de Galton se olvidó cuando Binet mostró que una aproximación puramente pragmática podía producir un test de inteligencia socialmente útil. La única asunción teórica de Binet, y que, además, podía ser directamente medida, fue que la capacidad mental de los individuos en una población era constante a lo largo del tiempo. Para elegir sus medidas, Binet estudió a expertos en la conducta escolar de los niños. Cualquier ítem se consideraba adecuado si se ajustaba a los estándares estadísticos de predicción del éxito académico posterior. La teoría psicométrica moderna ha aceptado la aproximación de Binet. El análisis factorial es un instrumento sofisticado para descubrir el número de ordenamientos relativos necesarios para dar cuenta de la ejecución en tareas intelectuales. Las estimaciones de este número van desde 2 (Cattell, 1971; Jensen, 1970) a 120 (Guilford, 1967). No obstante, no hay una teoría de la dinámica cognitiva que dicte nuestra elección de las preguntas a hacer. Un ítem es adecuado si muestra el patrón de correlación correcto. 
Creemos que Galton tenía razón, y no Binet. La medida en la ciencia debe estar guiada por la teoría. Por tanto, lo que se necesita es una teoría mejor.

Si la teoría es necesaria, entonces ¿por qué han prosperado los tests de inteligencia? A esta pregunta se puede responder de dos maneras. Una es afirmar que los ordenamientos relativos estables son adecuados para los propósitos tecnológicos de predicción. Esto es particularmente cierto cuando se considera a los tests como una técnica de extracción de un perfil personal. Si Harward necesita los mejores estudiantes disponibles y si IBM demanda los mejores vendedores del momento, entonces toda su necesidad se reduce a buscar una forma de ordenar a los individuos de la población de interés. El argumento a favor de un ordenamiento relativo es mucho más débil si estamos interesados en dar cuenta de la responsabilidad de una institución de proporcionar un determinado servicio a los miembros de determinada población; pero esta es una temática de reciente aparición en nuestra sociedad. ¿Es sosrprendente que al surgir esta temática, hayan brotado las suspicacias respecto a los tests?

Una segunda razón del éxito de los tests es que evaluan ciertos aspectos básicos de la cognición. Esto lo sabemos debido a que determinados cambios físicos en el cerebro afectan a las puntuaciones de los tests. Es bien conocido que el daño cerebral produce deterioro en la ejecución de los tests. De hecho, los daños específicos se pueden diagnosticar de acuerdo al tipo de deterioro en las puntuaciones de los tests (Reitan, 1964). Ejemplos particularmente representativos de la relación entre la biología de la cognición y la ejecución en los tests son la pérdida en las capacidades relacionadas con el habla después de un daño del cortex temporal izquierdo (Geschwind, 1970; Lenneberg, 1967), y la pérdida de la capacidad de aprendizaje de un material nuevo después de un daño del hipocampo (Milner, 1970). El hecho de que encontremos componentes genéticos sustanciales en la ejecución en los tests de inteligencia, sea cual fuere la amplitud de ese componente, es un indicador de que, de alguna manera, los tests de inteligencia miden algunas funciones biológicas básicas. Las diferencias individuales evaluadas por un tests de inteligencia son un reflejo útil de las diferencias biológicas y culturales entre los hombres, pero el desarrollo de estos tests ha dicho poco sobre la naturaleza de estas diferencias. Por esto, la evaluación intelectual es descriptiva y no prescriptiva.

Permitásenos centrarnos en el otro extremo. ¿Han aprendido algo sobre las diferencias individuales los científicos interesados en una teoria de la cognición? La respuesta es no. Los estudios modernos sobre la cognición, desde el punto de vista del procesamiento de la información, han revelado la existencia de un amplio conjunto de diferencias individuales, hasta tal punto que en muchos estudios se han tenido que utilizar diseños «intraindividuales» para intentar controlar la variabilidad intersujetos, para poder obtener resultados fiables. Este control ha sido necesario debido a que la psicología cognitiva pretendía establecer leyes generales aplicables a todos los hombres. De igual forma, la teoría del aprendizaje dominante en la psicología experimental no consideraba de interés central el hecho de las diferencias individuales, y la moderna teoría del aprendizaje ofrece escasa expliación de por qué los individuos reaccionan a las tareas de formas tan variadas (Estes, 1970). El hechọ de que se haya prestado escasa atención a 


\section{6}

las diferencias humanas en cognición es atribuible a la ingenuidad de los adictos al diseño experimental.

El motivo de esta narración histórica ha sido presentar al lector nuestra creencia de que, por una parte, se necesitan tests de inteligencia teóricamente fundamentados, y por otra, que se deben tomar en cuenta modelos útiles de la cognición para establecer las diferncias del funcionamiento mental. En lo que resta de este artículo intentaremos convertir al lector a nuestras creencias, mostrando que la inteligencia, tal y como se mide convencionalmente, está relacionada consistente y sustancialmente con ciertas variables claves de las teorías modernas de la cognición. Para poder hacer esto, describiremos, en primer lugar, un modelo general de la cognición y presentaremos algunas implicaciones que se derivan en relación a las diferencias individuales. Posteriormente discutiremos una serie de experimentos que relacionan el modelo y los actuales tests de inteligencia. Por último, consideraremos las implicaciones de estos resultados en la psicometría y en la psicología cognitiva, e indicaremos algunas direcciones para investigaciones futuras.

\section{EL MODELO DE MEMORIA DISTRIBUIDA DEL FUNCIONAMIENTO MENTAL}

El modelo teórico que vamos a utilizar es el Modelo de Memoria Distribuida (Hunt, 1971, 1973). Este modelo es representativo de un tipo de modelos aceptados por la mayoría de los psicólogos experimentales interesados en la cognición, aunque muchos de ellos podrían tener alguna reserva sobre ciertos detalles - y diferentes científicos tendrían diferentes reservas-. No plantearemos ningún tipo de defensa respecto al razonamiento que derivó en el modelo, o respecto a los resultados experimentales que lo sugirieron, puesto que esto se hizo en su momento.

La aproximación teórica subyacente al Modelo de Memoria Distribuida (MMD, a partir de ahora) es que el cerebro se puede entender como un sistema de computación (y no como un ordenador estrictamente), y que como tal, tiene una lógica construcción física que denominaremos arquitectura del sistema. Las estructuras físicas que comprenden la arquitectura del sistema son los procesos de control, análogos a los programas de un ordenador. Los procesos de control utilizan la arquitectura para manipular la información almacenada en una organización púramente lógica denominada estructura de datos. Para ilustrar esto desde la psicología, conceptos tales como «memoria a corto plazo" y "memoria permanente» son conceptos arquitectónicos, puesto que implican mecanismos de almacenamiento fijos, que sólo pueden utilizarse de determinada manera. Una estrategia de codificación, como el repaso o la conversión de una secuencia estímulo de ceros y unos en dígitos, en un proceso de control. El almacenamiento de la información en compartimentos conectados, tales como los enlaces subordinados y supraordinados entre los términos nominales sugeridos por Quillian (1968), o las posibles combinaciones de conexiones de subordinación-supraordinación y atributos, descritas por Meyer (1970) son conceptos de estructuras de datos. Un mensaje ambiental se supone comprendido cuando se ha incorporado a la estructura de datos. Esto se efectúa por la 
acción de los componentes arquitectónicos sobre el input y la información almacenada, bajo la dirección de un proceso de control.

La arquitectura del sistema del MMD se muestra en la Fig. 1. Se postulan dos clases de estadios de la información: estadios de retención periférica y estadios de memoria central. La información ambiental discurre a través de una serie de estadios de retención. Cada paso supone una recodificación que consiste, esencialmente en una interpretación del input en términos de la experiencia previa. Por ejemplo, una palabra escrita debe convertirse, desde la impresión retiniana puntual, en una serie de líneas, éstas en letras, y éstas últimas en una palabra. Subjetivamente, no obstante, vemos como mínimo la letra, y generalmente la palabra misma. Hay que destacar que el proceso de recodificación puede suponer el acceso a la información contenida en las áreas de memoria central. Esto se ilustra en una

FIGURA 1

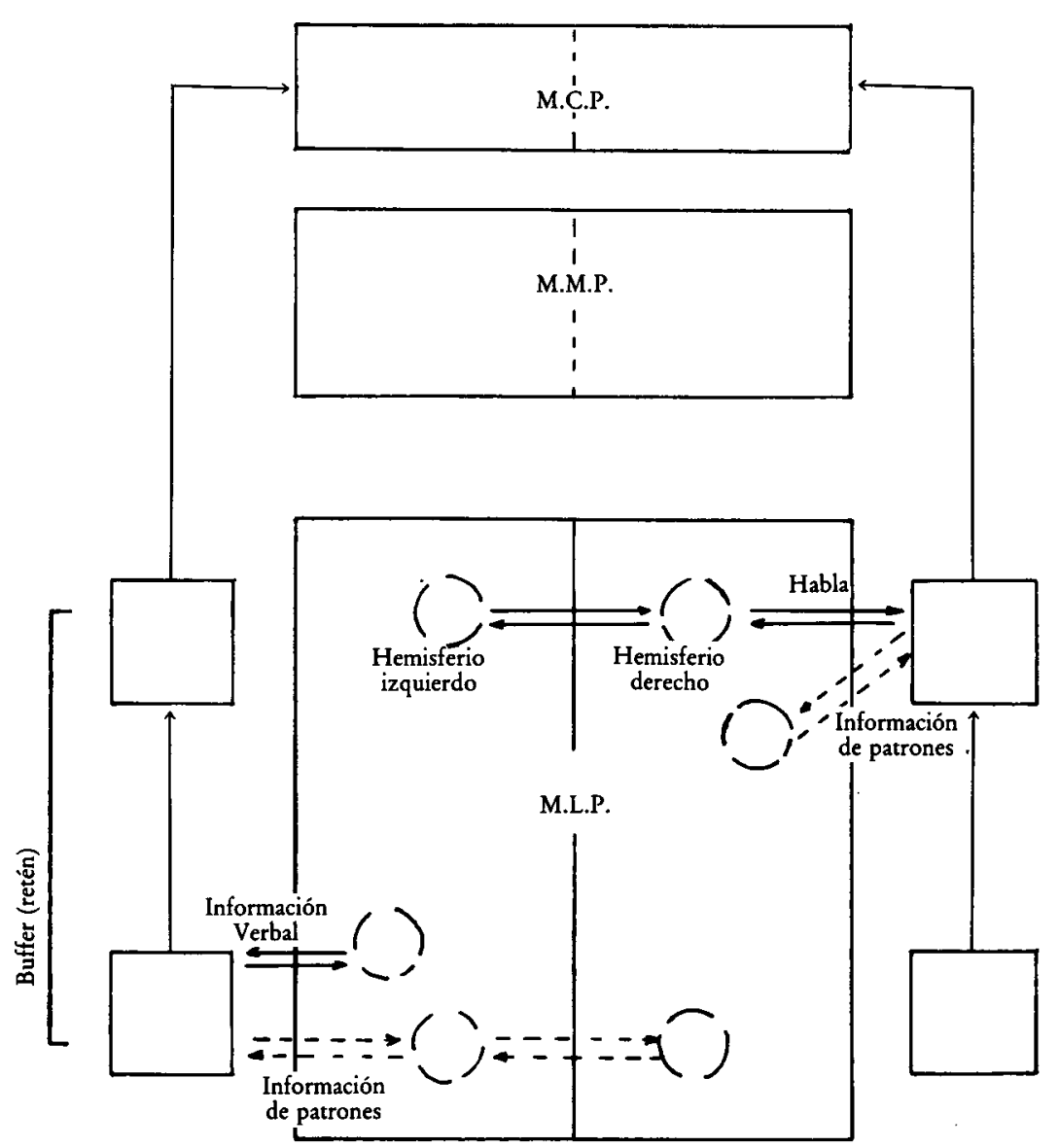


serie de excelentes experimentos de Posner y sus colegas (Posner y Boeis, 1971) con la "tarea de emparejamiento". Estos autores mostraron que se tardaba progresivamente más tiempo en reconocer dos estímulos como «iguales» o «diferentes» dependiendo de si la identidad se podía determinar físicamente (p.e. a = A) o se tenía que utilizar otro código más complejo, como por ejemplo el nombre de la letra (en cuyo caso a = A). Obviamente, el emparejamiento nominal sólo es posible sí el individuo conoce el alfabeto, y es bastante improbable que todo el alfabeto permanezca en la memoria a corto término. Menos científicamente, pero quizá más concluyentemente, existen numerosas anécdotas respecto a como una persona puede reconocer su nombre en medio de una conversación en una fiesta, y sin embargo, ignorar otras discusiones incluso con señales acústicas más altas.

Una vez que la información pasa por los procesos de retención, la información codificada accede a la memoria central. Se asume que la memoria central tiene tres componentes, a saber: la memoria a corto plazo (MCP) que mantiene el estímulo codificado durante breves segundos, la memoria a medio plazo (MMP) que retiene la codificación semántica del estímulo durante varios minutos o incluso durante una hora, y la memoria a largo plazo (MLP) que es el almacén permanente. Coloquialmente, la MCP proporciona un recuerdo palabra por palabra de lo dicho, la MMP proporciona un esbozo general del tema de la conversación, y la MLP mantiene lo que se conoce sobre la palabra más allá de la discusión concreta. La naturaleza de la codificación de la información en cada una de estos tipos de memoria es diferente. En la MCP los códigos son muy similares a los propiamente estimulantes. El sonido de las palabras parece jugar un importante papel. Los códigos de la MMP se refieren más a relaciones de tipo semántico. Puede ser útil contemplar los códigos de la MMP como grafismos que reflejan los términos básicos de un léxico, de manera similar a los grafismos de episodios o eventos propuestos por Rumelhart, Lindsay y Norman (1972), o el análisis de la estructura constituyente de sentencias de Schanck (1969).

Los códigos de la MLP juegan un papel similar a los términos de un diccionario. Estos códigos se organizan en algún tipo de red semántica, y constituyen bases de datos del sistema de recuperación de la información. En los estadios finales de la comprensión, la información se translada de la MMP a la MLP, donde se incorpora a las bases de datos de esta última. La organización de las bases de datos podría determinar si determinado bloque de información es difícil de recuperar, y la amplitud con la que la recuperación será sensible al contexto de la situación de recuerdo. Gran parte del reciente trabajo sobre agrupamiento, inhibición proactiva, comprensión de sentencias y recuerdo, pueden entenderse como parte de un intento de discernir la naturaleza del sistema de recupración. Un caso excelente podría ser la existencia de varias bases de datos, por ejemplo, la distinción de Tulving (1972) entre memoria semántica y episódica y la distinción entre sistemas de recuperación de información verbal y no verbal. Esta última dicotomía es de especial interés para nosotros. Por supuesto, habrá determinados procesos para los que la información de las diferentes bases de datos será transversal.

La distinción en diferentes tipos de bases de datos nos conduce a una 
segunda bifurcación de los componentes del sistema, en componentes del hemisferio derecho y componentes del hemisferio izquierdo. Sabemos que el cerebro humano es funcionalmente asimétrico. La evidencia fisiológica y clínica muestra que la MLP de la mayor parte de la gente para el habla se halla localizada en el córtex izquierdo (Gazzaniga, 1969). Esta división funcional tiene importantes implicaciones para una teoría del funcionamiento cognitivo. El hecho de la asimetría refuerza la afirmación de que la memoría de patrones y la memoria verbal son anatómica y lógicamente distintas. Para predecir la ejecución en una determinada tarea es necesario determinar la implicación de cada hemisferio y la importancia de la coordinación entre ellos, prestando particular atención a la eficiencia de la transferencia de información que se requiere.

Nuestro énfasis se centra en la localización y comunicación de los diferentes tipos de información. También nos interesa la transferencia de la información. Continuando con la analogía con el sistema de computación, debemos preguntarnos qué operaciones básicas sobre los datos se pueden realizar de acuerdo a los componentes del modelo. La compilación de una lista de funciones cerebrales básicas podría ser una tarea muy interesante, pero nosotros no lo haremos. En su lugar, trataremos de dos clases de transformaciones. Las transformaciones psicofísicas que tratan de la conversión de las señales del mundo exterior en códigos internos. Después de todo, sólo podemos pensar sobre las cosas que podemos sentir. Para nuestros propósitos, la importancia de las transformaciones psicofísicas viene determinada por la eficiencia del sistema de retención. Las manipulaciones internas en las memorias central y periférica son aquellas operaciones utilizadas para producir códigos internos nuevos a partir de otros códigos. Los estudios sobre cálculo mental de Restle (1970) y el estudio de la rotación mental de imágenes visuales de Shepard y Metzler (1971), son ilustraciones del tipo de experimentos que revelan estos procesos.

Idealmente, relacionar el MMD de la cognición y las diferencias individuales, supone desarrollar una teoría precisa de cómo se podría aplicar el modelo para resolver una serie de tareas intelectuales. Puesto que una determinada tarea se podría analizar desde diferentes perspectivas, consideraremos una serie de soluciones de programación para el ordenador humano. Encontraremos que la ejecución en algunas tareas será sensible al programa utilizado y para algunos parámetros del modelo, pero relativamente insensible a otras elecciones de programa y parámetros. Por ejemplo, la mayor parte de las situaciones de reconocimiento de palabras es sensible a la rapidez de la recuperación y a la organización de los datos en la MLP, pero insensible a la amplitud de la MCP; mientras que una tarea de amplitud se ve afectada por la cantidad de espacio de la MCP y los códigos disponibles en la MLP. Utilizando el análisis y la simulación, podríamos encontrar los parámetros y programas cruciales para determinar los diferentes tipos de ejecución intelectual. Los tests, a partir de este momento, podrían derivarse para medir directamente los parámetros o el programa utilizado. Estos tests podrían, colectivamente, ser una medida de la inteligencia teóricamente basada. Este propósito deberá llevarse a cabo sólo si-se tiene una esperanza razonable de éxito. Aquí intentaremos lograr la meta de mostrar que el éxito puede lograrse. Mostraremos que existen relaciones entre los tests de inteligencia actuales y la mayor parte de las variables del modelo. Nos 
centraremos en los componentes de la memoria, puesto que se someten a análisis en la mayor parte de los estudios recientes. ¿Podemos encontrar evidencia respecto a la existencia de una separación de los talentos de memoria con diferentes relaciones respecto a los factores de la inteligencia, a través del estudio de las diferencias individuales? Nuestra meta no es mostrar que los parámetros de los modelos de la cognición pueden ser utilizados para predecir las puntuaciones de inteligencia, o viceversa. Si esto fuese así, las dos medidas contendrían la misma información. Deseamos mostrar dos cosas: primero, que existe una relación sustancial, pero imperfecta, entre un modelo de la cognición humana y los tests, p.e. que las medidas aportan información, pero no idéntica; $y$, segundo, que las diferencias en las reacciones de los sujetos a las tareas experimentales son funciones fiables de las características individuales, y que no puede conceptualizarse propiamente como medidas de error.

\section{EL PLAN DE INVESTIGACIÓN}

Se seleccionaron y replicaron los estudios más influyentes en el desarrollo de nuestro modelo del pensamiento. La inteligencia se tomó como variable independiente. Para poder llevar a cabo esta tarea, necesitábamos sujetos de los que dispusiesemos los datos psicométricos imprescindibles. Si nuestra aproximación teórica es correcta, será posible desarrollar un patrón consistente del funcionamiento mental de un individuo. Por tanto, nuestros sujetos podían ser examinados en una serie de tareas experimentales. Idealmente, nos habría interesado extraer a los sujetos de una población con un amplio rango de variación en una serie de factores intelectuales, puesto que de esta manera aumentaría la sensibilidad de nuestras medidas. Pero, puesto que las consideraciones administrativas imposibilitan este ideal, utilizamos a estudiantes de la Universidad de Washington que, antes de su ingreso, habían cumplimentado una batería estándar de tests de inteligencia - la Batería "Precollege» de Washington (WPC) - Esto es parte del programa aplicado a todos los estudiantes de high schools del Estado de Washington, y es un requisito para todo aquel que pretenda ingresar en la Universidad. Se aplica generalmente al finalizar la bigh school. La batería contiene nueve tests de inteligencia relacionados: Vocabulario (antónimos), Uso del inglés (gramática, utilización, dicción, e idioma), Ortografía (reconocimiento de faltas de ortografía), Lectura (distintos niveles de comprensión y rapidez), Habilidades Cuantitativas (razonamiento), Matemática aplicada (número de habilidades, aplicaciones aritméticas), Logro en $\mathrm{Ma}$ temáticas (curriculum), Capacidad Espacial (visualizaciónde manipulaciones en un espacio tridimensional), y Razonamiento Mecánico (aplicación de principios físicos). Además de las puntuaciones para cada uno de los tests de la batería, se disponía de dos medidas compuestas resultado de un análisis factorial. La Puntuación de Capacidad Verbal (CV) era resultado de una suma ponderada de las ejecuciones en Vocabulario, Uso del Inglés, Ortografía, Comprensión Lectora, y Rapidez de Lectura. La Capacidad Cuantitativa (CC) era resultado de una suma ponderada de las Habilidades Cuantitativas, Matemáticas Aplicadas, y puntuaciones de logro en Martemáticas. Utilizamos estas dos medidas compuestas para clasificar a los su- 
jetos. Estas puntuaciones son representativas de las medidas en inteligencia verbal y cuantitativa ampliamente empleadas con sujetos adolescentes - las medidas compuestas correlaccionan .81 y .85 con los subtests verbales y matemáticos del Test de Aptitudes de examen de ingreso en la escuela, y es comparable a las fiabilidades test-retest de las subpuntuaciones de la SAT.

Debido a la amplia aceptación de estas medidas verbales y cuantitativas como dos de los más importantes aspectos de la inteligencia, seleccionamos como sujetos a los estudiantes con puntuaciones extremas. Los sujetos ubicados en los cuartiles extremos recibieron una invitación para participar como sujetos experimentales remunerados. Puesto que los sujetos representaban extremos de la población universitaria, los sujetos con puntuaciones bajas se situaban una desviación estándar por debajo de la medía en relación a las puntuaciones obtenidas mediante el WPC. Los sujetos del extremo superior se situaban una desviación estándar por encima de la media. Esta distribución se debe a la política de selección de la Universidad de Washington. En general, los estudiantes que ingresan se sitúan en el tercio superior de las clases de graduación de la high school.

Las respuestas a las invitaciones fueron muy positivas. Nuestro panel eventual de sujetos consistió en 104 sujetos que residieron en la Universidad durante el año académico 1971-1972. La Tabla I muestra la distribución de sujetos en cuatro grupos definidos por las combinaciones de los cuartiles superiores e inferiores en capacidad verbal y cuantitativa. No todos los sujetos participaron en todos los experimentos.

\section{TABLA I}

Número de sujetos en cada cuartil de aptitud cuantitativa $\ddot{u}$ verbal

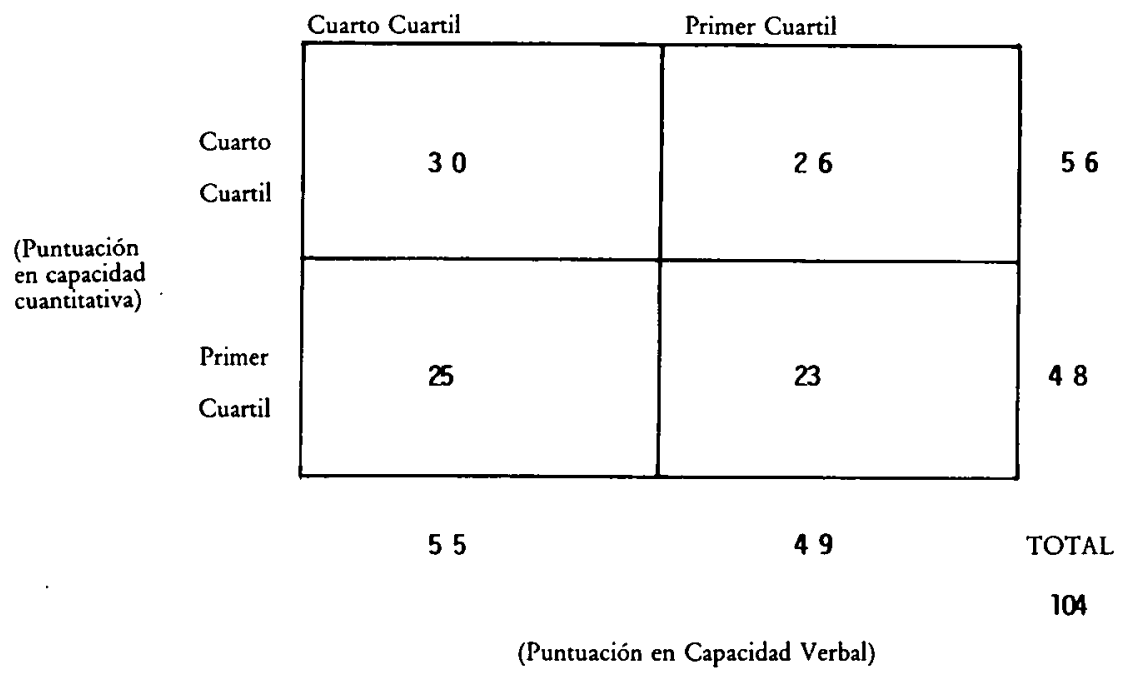

Presentaremos nuestros resultados en un orden lógico, describiendo inicialmente dos experimentos "globales» que pongan a prueba varios aspectos del funcionamiento de la memoria. Posteriormente, describiremos otros experimentos que analicen aspectos más específicos. 


\section{EXPERIMENTOS GENERALES}

\section{Experimento de Pares Asociados}

Atkinson y Shiffrin $(1968,1971)$ han desarrollado un modelo de dos estadios para la tarea de pares asociados. La tarea requiere que el sujeto retenga la asociación entre cada una de los conjuntos de estímulos, y uno de un amplio conjunto de respuestas, aunque la asociación cambie sistemáticamente. Por ejemplo, supongamos que los estímulos sean las letras A-D, y las respuestas se seleccionen de entre una serie que oscila entre 00 y 99. Una secuencia de presentaciones que utilice el método de la anticipación puede ser:

A-47

B-12

C-39

D-17

B-?

B-73

A-?

A-7

ensayos iniciales

primer ensayo de prueba, retardo $=2$

primer ensayo de estudio después de un ensayo de prueba segundo ensayo de prueba, retardo $=4$

segundo ensayo de estudio

La secuencia de presentación se divide en tres tipos de ensayos. En primer lugar, los ensayos iniciales, en los que cada estímulo se empareja con una respuesta. En el ensayo de prueba, se presenta el estímulo sólo y el sujeto debe establecer el número más reciente emparejado con el estímulo. El ensayo de prueba es seguido por un ensayo de estudio, en el que el estímulo puesto a prueba se empareja con una nueva respuesta. En nuestros experimentos, se rpesentaron 150 pares de ensayos estudio-prueba. La tarea tenía altas cotas de demanda, y los porcentajes de error eran elevados. La variable independiente interesante era el retardo, definido como el número de pares entre el ensayo de estudio y el ensayo de prueba para determinado estímulo. En la ilustración, se muestran ejemplos de retardo 2 y retardo 4.

El modelo de Atkinson y Shiffrin para analizar los datos de estas tareas proporciona una estimación de cuatro parámetros: $\alpha$, la probabilidad de que un ítem acceda a la MCP; $\varrho$, el número de ítems que se pueden retener simultáneamente en la $\mathrm{MCP} ; \theta$, la proporción de información transferida a la MMP; y $\chi$, la proporción con la que la información no está disponible en la MMP. El modelo se ajusta bastante bien a los datos. De especial interés para nuestros fines, es observar que se encuentran sustanciales diferencias individuales cuando se estiman los parámetros para cada sujeto (Atkinsonb, Brelsford y Shiffrin, 1967).

Cuarenta sujetos, diez de cada uno de los cuatros subgrupos, participaron en una replicación del experimento de Artkinson y Shiffrin. El estudio se controló mediante ordenador. Los estímulos fueron cuatro triagramas consonante-vocal-consonante (CVC), y las respuestas fueron pares de dígitos de valores entre 01 y 75 . Se realizaron cuatro ensayos para emparejar inicialmente cada estímulo con una respuesta, y posteriormente se aplicaron secuencias de 150 ensayos estudio-prueba. La duración de cada 
ensayo estudio-prueba suponía 3 segundos. El lapso temporal entre los ensayos de prueba fue controlado por los sujetos. El retardo entre un ensayo de estudio y su subsecuente prueba varió desde 1 a 14. Los detalles adicionales se rigieron por el procedimiento de Atkinson y Shiffrin (1968).

Se estimaron los parámetros para cada sujeto utilizando la técnica de minimización chi-cuadrado desarrollada por Garnatz y Hunt (1973). La Tabla II muestra la media y la desviación estándar de cada parámetro para cada grupo, y para los grupos combinados. Es aparente la existencia de amplias diferencias individuales, y algunas de ellas están relacionadas con el WPC. La diferencia más destacable es que la proporción de pérdida de recuperación de la información de MMP fue fiablemente más baja para los

\section{TABLA II}

Medias y desviaciones típicas para estimar los parámetros en la tarea de pares asociados

Estimaciones paramétricas

\begin{tabular}{lllllllllll}
\hline & $\alpha$ & & & $\tau$ & & & $\theta$ & & \multicolumn{2}{c}{$\lambda$} \\
\hline & & & & & & & & \\
\hline & DT & $\mathbf{X}$ & DT & & $\mathbf{X}$ & DT & $\mathbf{X}$ & DT \\
\hline
\end{tabular}

Cuantitativa

Alta

$\begin{array}{lllllllll}\text { Alta } & & & & & & & \\ \text { Verbal } & .50 & .56 & 1.75 & 1.93 & .32 & .36 & .75 & .84 \\ \text { Baja } & & & & & & & & \\ \text { Verbal } & .38 & .34 & 1.65 & 1.88 & .28 & .33 & .74 & .61\end{array}$

Media para los grupos de alta cuantitativa

Cuantitativa

Baja

Alta
Verbal
Baja
Verbal
.24

.43

1.23

1.87
1.44

.27

.29

.52

.84

$\begin{array}{lll}.32 & .38 & .30\end{array}$

.40

Media para los grupos de baja cuantitativa

N.S.

$\mathbf{p}<.002$

\footnotetext{
* Se indican los tests de alta significación de alta y baja capacidad cuantitativa. No se encon-
} traron diferencias significativas para el grupo verbal compuesto. 
grupos de alta capacidad cuantitiva $\left(\mathrm{F}_{1,36}=14.62, \mathrm{p}<.002\right)$. Esto sugiere que los sujetos de alta puntuación en capacidad cuantitativa tienen también una alta probabilidad de retener un ítem en $\operatorname{MCP}\left(F_{1,36}=5.00, p<.10\right)$. Ninguna de las restantes diferencias individuales parecían asociarse con las puntuaciones en los test de inteligencia. Es interesante observar que los parámetros $\theta, \varrho$, y $\alpha$ se consideran bajo el control de los sujetos, en el sentido de que sus valores pueden ser manipulados por la elección de la estrategia para enfrentarse a la tarea experimental (Loftus, 1971). Por tanto, los valores de éstos parámetros exhibirán amplias diferencias individuales cuando los sujetos no tengan suficiente práctica como para estabilizarse en una estrategia común. A diferencia de Atkinson y Shiffrin, no permitimos que los sujetos se familiarizasen con la tarea. La medida de la pérdida efectiva de información de la MMP, por otro lado, se supone que es una medida del grado en el que el sujeto se distrae por la información entrante, después de haber fijado un ítem en la memoria. Como tal, debe estar en menor medida bajo el control del sujeto.

\section{Agrupamiento}

Se eligió la tarea de Atkinson y Shiffrin porque representa una tarea global que permite poner a prueba varios aspectos de la memoria, sin despreciar el significado ligüístico de los estímulos. Ahora, permitásenos considerar una segunda tarea global -el recuerdo libre de una lista organizada de palabras-. Es bien conocido que en el recuerdo libre de listas de palabras, los sujetos intentar imponer alguna organización a la hora de responder. Por ejemplo, en el recuerdo libre de palabras no relacionadas, las respuestas seguirán el orden de presentación de los estímulos, incluso cuando no se les pide a los sujetos que lo hagan. Otra estrategia generalmente utilizada en el recuerdo libre es recordar palabras juntas si están semánticamente relacionadas de alguna manera. Por ejemplo, palabras libremente asociadas, como HILO y AGUJA se recordarán generalmente juntas despreciando su posición en la lista estimular. Un tipo particularmente interesante de agrupamiento es el agrupamiento semántico de categorías (Bousfield, 1953). Si presentamos una lista de palabras, por ejemplo, de nombres de animales, vegetales y minerales, entonces los miembros de cada categoría se recordarán juntos. El fenómeno es incluso más pronunciado si la lista está bloqueada, p.e. si todos los términos de una categoría se presentan juntos cuando se presenta la lista (Cofer, Bruce y Reicher, 1966; Puff, 1966). El estudio de Puff del efecto de bloqueo se seleccionó para explicarlo. Intuitivamente esperábamos una ejecución más sensible a la facilidad verbal en esta tarea que la ejecución en la tarea de recuerdo de pares asociados.

Los sujetos recordaban listas de nombres agrupados en categorías semánticas, presentadas en forma categorizada o aleatorizada. Este estudio permitía al sujeto organizar su memoria en referencia a las categorías semánticas, y nos permitía observar la amplitud con la que su organización del recuerdo se veía influida por las condiciones de presentación.

Participaron 12 sujetos de cada uno de los cuatro grupos. Cada sujeto aprendía dos listas de 30 palabras, e inmediatamente se le pedía que recordase. Cada lista contenía diez palabras de cada una de las siguientes categorías: 
Lista A - vegetal, ocupación, animal

Lista B - fruta, término geográfico, utensilio de cocina

En la condición de bloqueo todas las palabras de una categoría se presentaron en una relación de contigüidad; en la condición pseudoaleatorizada las palabras de diferentes categorías se mezclaron, de forma que sólo en nueve casos se presentaron dos palabras de la misma categoría juntas en la lista. El orden de presentación y la organización de las listas A y B se balanceó a través de los sujetos. Cada lista se presentó por duplicado, y se pidió el recuerdo libre después de cada presentación. Dentro de cada lista, cada item se presentaba durante 2,5 segundos, con un intervalo entre presentación de 1,5 segundos. Todos los demás detalles del estudio mimetizaron el trabajo original de Puff. En el recuerdo libre se puntuó el número correcto y el número de repeticiones de la categoría, en relación al número máximo de posibles repeticiones. El grado en el que la codificación semántica es sensible al orden de presentación era inferible a partir de las puntuaciones de la repetición categórica, o agrupamiento, bajo las dos condiciones de presentación de la lista.

TABLA III

Categoria promedio de las puntuaciones en agrupamiento para los cuatro subgrupos

Puntuación Media en agrupamiento

\begin{tabular}{lccc}
\cline { 2 - 3 } Grupo & $\begin{array}{c}\text { Condición } \\
\text { de bloqueo }\end{array}$ & $\begin{array}{c}\text { Condición pseudo- } \\
\text { aleatorizada }\end{array}$ & Diferencia \\
\hline $\begin{array}{l}\text { Alta Verbal } \\
\text { Alta } \\
\text { cuantitativa }\end{array}$ & .96 & .70 & .26 \\
$\begin{array}{l}\text { Baja } \\
\text { cuantitativa }\end{array}$ & .96 & .68 & .28 \\
$\begin{array}{l}\text { Media alta } \\
\text { verbal }\end{array}$ & $.96(26.6)$ & $.69(23.9)$ & .27 \\
$\begin{array}{l}\text { Baja Verbal } \\
\text { Alta } \\
\text { cuantitativa }\end{array}$ & .86 & .82 & .04 \\
$\begin{array}{l}\text { Baja } \\
\text { cuantitativa }\end{array}$ & .96 & .85 & .11 \\
$\begin{array}{l}\text { Media baja } \\
\text { verbal }\end{array}$ & $.91(25.4)$ & $.84(23.0)$ & .07 \\
\hline
\end{tabular}

La Tabla III presenta los resultados. No se presentaron diferencias en el número total de palabras recordadas. El agrupamiento fue alto para todos los sujetos en la condición de bloqueo. No obstante, se encontraron diferencias sustanciales entre los grupos en la condición pseudoaleatorizada. Los resultados fueron contraintuitivos - los sujetos de alta capacidad verbal mostraron un notable descenso en la cantidad de agrupamientos cuando no se trataba de la lista bloqueada, mientras que los sujetos de baja capacidad verbal mantenían su nivel-. No obstante, los sujetos de alta ca- 


\section{6}

pacidad verbal no utilizaban un recuerdo aleatorizado. En palabras de varios sujetos, se limitaban a «leer las palabras retrospectivamente». Esto se refleja (débilmente) en los datos por una tendencia no significativa de los sujetos de alta capacidad verbal a responder enumerando los ítems en su orden de presentación. En cualquier caso, fuese lo que fuese lo que hicieron los sujetos de alta capacidad verbal, los datos y sus informes fueron consistentes para rechazar la hipótesis de que utilizaban el agrupamiento tanto como los sujetos de baja capacidad verbal.

\section{EXPERIMENTOS DETALLADOS}

\section{Codificación}

Un concepto importante del modelo de memoria distribuida es la idea de los niveles de codificación estimular. Previamente hemos ilustrado este aspecto en referencia a la tarea de emparejamiento físico y nominal desarrollada por Posner y sus asociados. Estos estudios proporcionan el paradigma de nuestro siguiente experimento. En una variación secuencial del método de Posner y asociados, se les muestra a los sujetos una primera letra inmediatamente seguido de una segunda, que debe identificarse como «igual" o "diferente» dependiendo de si la identidad es física o nominal. Un sujeto con práctica suele utilizar $70 \mathrm{msg}$ más en realizar un emparejamiento nominal que en efectuar un emparejamiento físico.

Dieciséis sujetos, cuatro de cada uno de los subgrupos, cumplimentaron una tarea de emparejamiento físico y nominal durante una sóla sesión experimental. La tarea requiere que un sujeto mire una letra presentada durante 1 segundo. Después de que la letra desaparece, se presenta una segunda letra, con un intervalo interestímulos de cero segundos. En la condición de emparejamiento físico, el sujeto debe responder IGUAL si las letras son físicamente idénticas (p.e. AA); en la condición de emparejamiento nominal, los sujetos responden IGUAL si las dos letras tienen el mismo nombre (p.e. AA y Aa). Las respuestas se efectúan presionando una serie de botones de un teclado. Los sujetos practicaron con 160 ensayos antes de comenzar el experimento; la mitad de los sujetos realizaron en primer lugar la tarea de emparejamiento nominal, mientras que la otra mitad realizaron la tarea de emparejamiento físico en primer lugar. Cada sujeto recibió 40 ensayos iguales y 40 ensayos diferentes en cada condición. En cualquier caso, la forma física de la segunda letra fue predictible (i.e. se utilizó la lista de Posner).

Los datos se presentan en la Tabla IV. Aún a pesar del escaso número de sujetos y el pequeño entrenamiento (en comparación con el procedimiento utilizado por Posner) se hallaron diferencias significativas $(\mathrm{p}<.08)$ entre los grupos de alta y baja capacidad verbal, utilizando el estadístico de Mann-Whitney. Ningún otro contraste alcanzó el nivel de significación. Por desgracia, el período vacacional, y la consiguiente desaparación de la muestra, imposibilitó replicar este estudio con un grupo más extenso, por lo que los resultados encontrados son sólo sugestivos. Las diferencias halladas sugieren que esta puede ser un área de estudio interesante. La diferencia se debe a la diferencia en tiempo respecto al emparejamiento nominal; en el emparejamiento físico los sujetos de alta capacidad verbal sola- 


\section{7}

TABLA IV

Diferencias temporales en emparejamiento fisico $\ddot{u}$ nominal para los cuatro subgrupos (milisegundos)

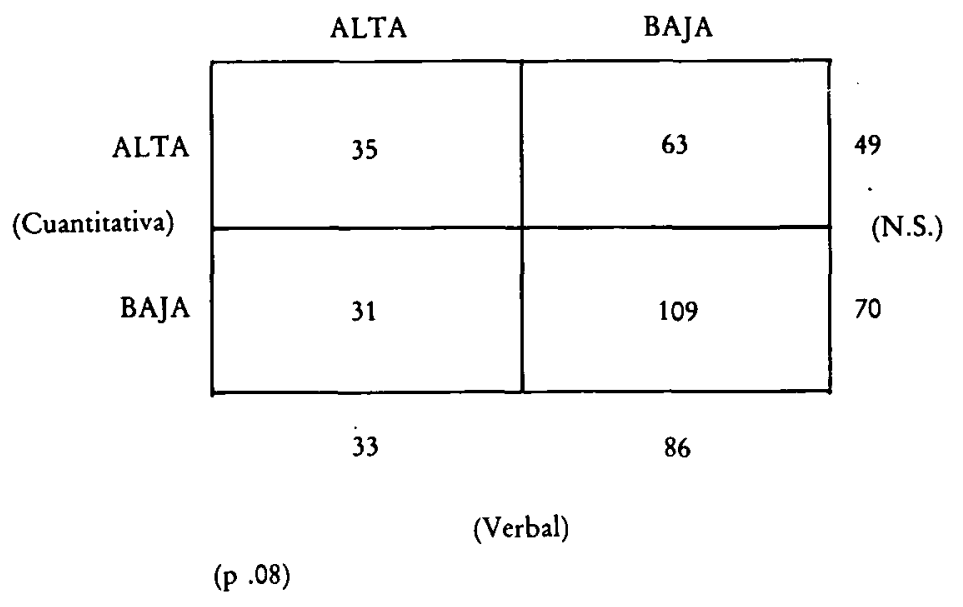

mente son 12 msg más rápidos que los sujetos de baja capacidad verbal. En otras palabras, el efecto que se muestra en la Tabla IV se debe al acceso nominal más rápido de los sujetos de alta capacidad verbal.

\section{Codificación semántica y descarga de la inhibición proactiva}

La codificación que supone la tarea de Posner y asociados es sólo física y taxonómica. Consideraremos ahora un tipo de codificación que implica una codificación de MLP de mayor rango. Wickens y asociados ha llevado a cabo una serie de estudios sobre la descarga en el fenómeno de la inhibición proactiva realizando experimentos de MCP (Wickens, 1970). Es bien sabido que si se le pide a una persona que mantenga en su MCP entre 3 y 6 chunks de información, mientras ejecuta una tarea distractora, como por ejemplo contar hacia atrás, se producirá el olvido en breves segundos. El fenómeno depende parcialmente de la inhibición proactiva, puesto que no ocurre en el primer ensayo, y aparece rápidamente el nivel asintótico en tres o cuatro ensayos. Wickens encontró que el incremento del IP se ve afectado por la constancia de la significación estimular. Por ejemplo, si se le presentan a un sujeto triagramas consonante-vocal-consonante, se presentará IP. Supongamos que utilizamos el ensayo $n+$ primero, en lugar de la secuencia de números de tres dígitos, como el estímulo a recordar. El sujeto no presentará tasas de olvido en este tipo de ensayo. Esto se refiere a la descarga de la IP. La IP se presenta de nuevo, en nuestro ejemplo, presentándole al sujeto otra secuencia de ensayos estándar C-V-C. El efecto de descarga de la IP se puede demostrar, bien cambiando a estímulos con diferentes características acústicas o semánticas - p.e. de U, C, D a A, X, $\mathrm{R}$, o de letras a números, $o$ incluso de una categoría nominal a otra-. Pero consideremos los resultados de los estudios de emparejamiento nominal. 
Sugieren que la rapidez de codificación lingüistica del material está relacionada con la capacidad verbal. ¿Presentará la sensibilidad a la codificación lingüística del significado una relación similar?.

24 sujetos, seis de cada uno de los subgrupos, participaron en un experimento de descarga de la IP. En cada ensayo, el sujeto leyó tres nombres de vegetales, contó hacia atrás durante un intervalo variable entre 3 y 15 segundos, y se le pidió que recordase los nombres de los vegetales. Después de tres ensayos de este tipo, se cambió la categoría estimular de vegetales a ocupaciones, manteniendo constantes las otras condiciones experimentales. Un segundo grupo de 24 sujetos participó en una condición control, en la que no se produjeron cambios de categoría.

FIGURA 2
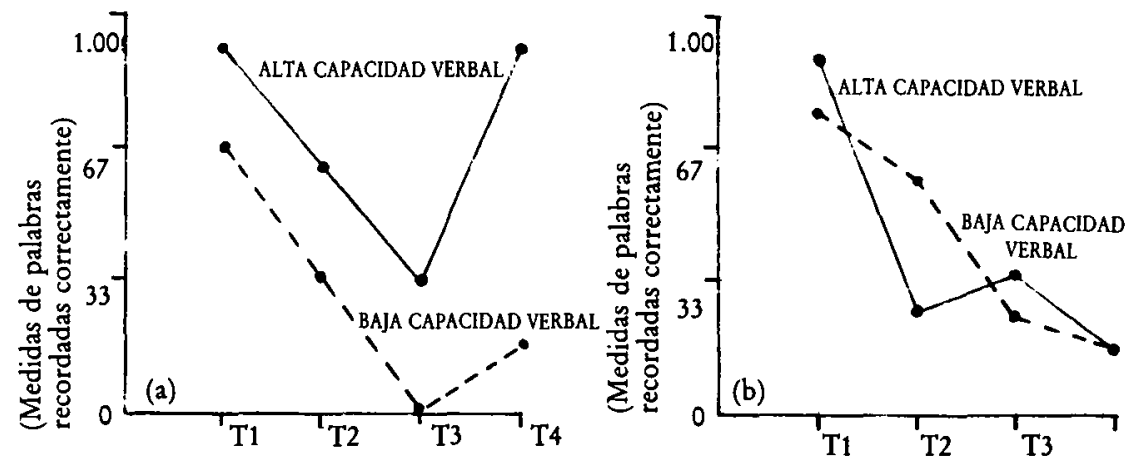

Descarga de la inbibición proactiva; sólo se puntuó correctamente si el sujeto recordaba en el orden de presentación. (a) 12 sujetos de alta capacidad verbal, y 12 de baja; condición experimental. (b) Idem: condición control

Los resultados se muestran en las figuras 2 y 3 . En la figura 2 se puede ver que la IP se presenta en los tres primeros ensayos, tanto en el grupo experimental como en el control. El fenómeno de descarga de la IP aparece más marcadamente en los sujetos de alta capacidad verbal. No obstante, los datos que se muestran en la figura 2 resultaron de puntuar correctamente sólo si un sujeto recordaba todas las palabras en el orden de presentación. En la figura 3 podemos ver los mismos datos, pero puntuados según el recuerdo de una palabra (ignorando los errores de posición serial). En este segundo caso, los datos indican que la descarga categorial de IP se acentúa en ambos grupos. Este resultado se afianzó a través de un análisis de varianza, de donde surgió una interacción significativa $(p<.025)$ entre la capacidad verbal y el método de puntuación. Las diferencias que se presentan en la figura 2, por tanto, no se deben a la codificáción categórica, sino al deterioro de la codificación temporal a través de los ensayos en los grupos de baja capacidad verbal. Esto es muy interesante, debido a que la codificación temporal y la rapidez de codificación son conceptos estrechamente relacionados. Los datos también sugieren que en el estudio de agrupamiento los sujetos de baja capacidad verbal utilizaron información semántica, debido a que no podían recuperar los códigos de posición serial. Retrospectivamente, podemos recordar la elocuente discusión de Lashley (1951) sobre los problemas de posición serial en la comprensión lingüísti- 
ca. Una memoria superior para el orden de la información puede incrementar la puntuación verbal típica de un tests de CI. También diremos que la codificación temporal está estrechamente relacionada con los factores referidos a la rapidez cognitiva.

FIGURA 3
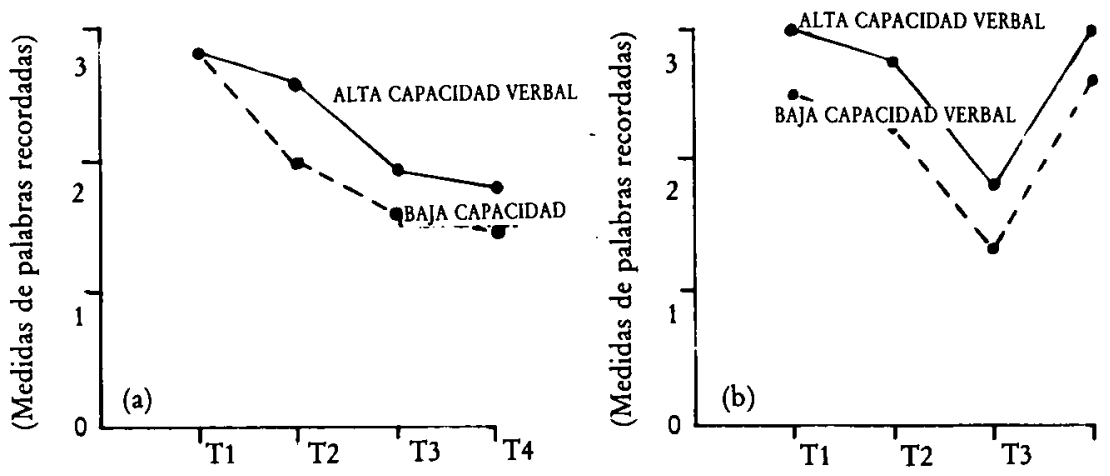

Datos de inhibición proactiva sin tener en cuenta el orden de presentación. Idem figura 2 (condiciones experimentales)

\section{Manipulación de la información en MCP}

Al describir un sistema de computación se suele establecer el tiempo de acceso a memoria, aspecto que determina la rapidez de procesamiento de los datos. Sternberg $(1966,1970)$ ha desarrollado un paradigma para estudiar la rapidez con que la gente accede a los datos de MCP. En primer lugar, el sujeto se le presenta un pequeño conjunto de ítems familiares que debe retener en la memoria. A esto se la denomina conjunto mnemónico. Se suelen utilizar secuencias de letras o dígitos. Se presenta un ítem de prue$\mathrm{ba}, \mathrm{y}$ se le pide al sujeto que indique si ese ítem pertenece al conjunto mnemónico. Se supone que el tiempo de respuesta es una función lineal del número de ítems del conjunto mnemónico. La pendiente de la función se interpreta como una medida del tiempo necesario de acceso a un sólo ítem de la MCP y al tiempo de comparación con el de prueba. Las pendientes varían según el tipo de material, pero virtualmente todos los estudios presentan diferencias individuales pronunciadas.

16 sujetos -8 de baja y 8 de alta capacidad verbal - se sometieron a la prueba de Sternberg. Se presentaron simultáneamente durante 3 segundos de uno a cinco dígitos. El digito de prueba aparecía 2 segundos más tarde. Los sujetos se hicieron con la prueba rápidamente. Las latencias de respuesta, en función de la amplitud del conjunto, se presentan en la figura 4. Los sujetos de alta capacidad vebal eran significativamente más rápidos, pero no hubo correlación entre el grado de búsqueda y las puntuaciones en capacidad cuantitativa $(r .=.09)$. Además, no hubo correlación entre la pendiente y la intercepción, lo que demuestra que los resultados no reflejan simplemente la diferencia entre sujetos conservadores e impulsivos. Los resultados son consistentes con los resultados del estudio de empare- 
jamiento nominaí, al indiciar que la capacidad verbal está relacionada con la rapidez de manipulación de los datos en la memoria.

FIGURA 4

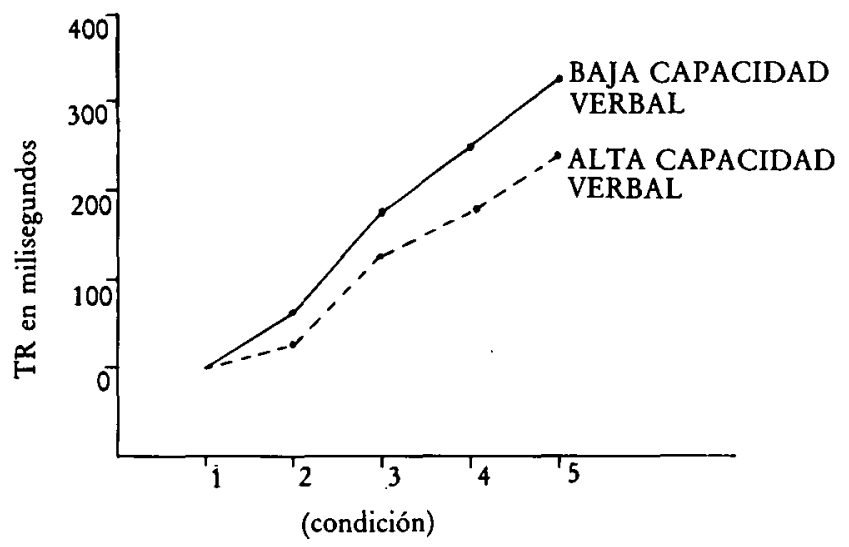

Tiempo de reacción para los items de prueba correctamente reconocidos, de acuerdo al número de items del conjunto mnemónico. Los puntos representan el promedio de $T R$ en cada condición menos la medida de TR para la condición 1

\section{Susceptibilidad a la interferencia}

En el siguiente estudio, vamos a estudiar la capacidad cuantitativa. El estudio de pares asociados sugirió de los sujetos de alta capacidad cuantitativa tienen una alta resistencia a la interferencia después de adquirir información. Ahora trataremos este aspecto más directamente.

18 sujetos de alta y 10 de baja acapacidad cuantitativa, participaron en un estudio de replicación del paradigma de Brown-Peterson (Peterson y Peterson, 1959). Se situó al sujeto en una cabina de atenuación sonora, y se le presentó un triagrama $\mathrm{C}-\mathrm{C}-\mathrm{C}$ mediante auriculares, a lo que siguió inmediatamente un número de tres dígitos. Los sujetos contaron hacia atrás a partir de éste número de tres en tres, durante $3,6,9,12,15$ ó 18 segundos, y después de una señal, trataban de recordar el triagrama. Se presentaron cuatro ensayos por intervalo.

Los datos se presentan en la figura 5. Los sujetos con puntuaciones altas en capacidad cuantitativa mostraron una ejecución consistentemente mejor en todos los intervalos de retención $(\mathrm{p}<.05)$, por lo que el hecho de que los sujetos de alta capacidad cuantitativa ejecuten adecuadamente en esta tarea (no cuantitativa) es claro. Se pueden plantear tres hipótesis: que los sujetos de alta capacidad cuantitativa son generalmente menos susceptibles a la distracción, al percibir la información y al intentar retenerla en la memoria; que los sujetos de alta capacidad cuantitativa tiene un buffer de MCP mayor, y por tanto, son más capaces de mantener más información en la MCP durante un determinado lapso temporal; o que los sujetos de alta capacidad cuantitativa poseen procesos de memoria menos susceptibles a la interferencia.

Como forma de contrastar la primera hipótesis, se utilizó una condición «ruidosa» del paradigma de Brown-Peterson, con los mismos 28 su- 


\section{1}

jetos. El experimento fue idéntico al principal, excepto por el hecho de que los estímulos se presentaron sobre un ruido blanco de fondo, ajustado para que estímulo fuese audible en un intervalo durante el $50 \%$ del tiempo. $\mathrm{Si}$

FiguRA 5

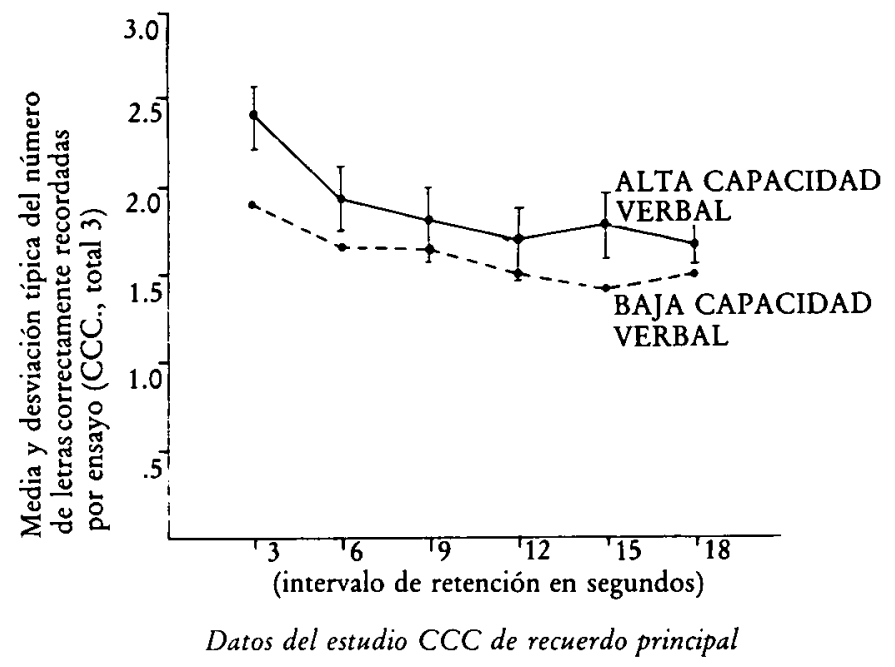

los sujetos de alta capacidad cuantitativa son capaces de percibir la información, presentarán una superioridad clara bajo esta condición. Los datos se muestran en la figura 6. Ambos grupos presentaron un efecto suelo. Por esto, no se puede decir que la alta capacidad cuantitativa esté asociada a la habilidad para desatender los estímulos distractores físicos per se.

Si los sujetos de alta capacidad cuantitativa tiene una MCP mayor, entonces serán capaces de retener más información en la MCP en una tarea de amplitud de memoria. Esta cuestión se estudió directamente en otro estudio, con 18 sujetos de alta y 12 de baja capacidad cuantitativa. Los dígitos se presentaron a razón de uno por segundo. Inmediatamente después de la presentación de una secuencia de dígitos, los sujetos recordaban tecleando la secuencia en un ordenador. El número de dígitos de la secuencia se aumentó gradualmente hasta que el sujeto no fue capaz de responder correctamente. Las puntuaciones de los sujetos de alta capacidad cuantitativa alcanzaron un promedio de amplitud de memoria de 7.44, y los sujetos de baja puntuación una media de 7.42. La diferencia entre los dos grupos no fue estadísticamente significativa. Además, una puntuación en amplitud de memoria de este tipo cae dentro de rango normal. Por esto, no se apoya la idea de que los sujetos de alta capacidad cuantitativa tiencn una MCP excepcionalmente amplia.

Para encararnos con la tercera hipótesis, hemos de comenzar diciendo que el paradigma de Brown-Peterson tiene dos causas potenciales de interferencia: IP desde los ensayos previos, e interferencia retroactiva debida a los efectos de la tarea distractora (contar hacia atrás) mientras se mantiene la información en la memoria. Los datos no permiten distinguir cuál de estos dos tipos de causas es sensible al nivel de capacidad cuantitativa. De- 
FigURA 6

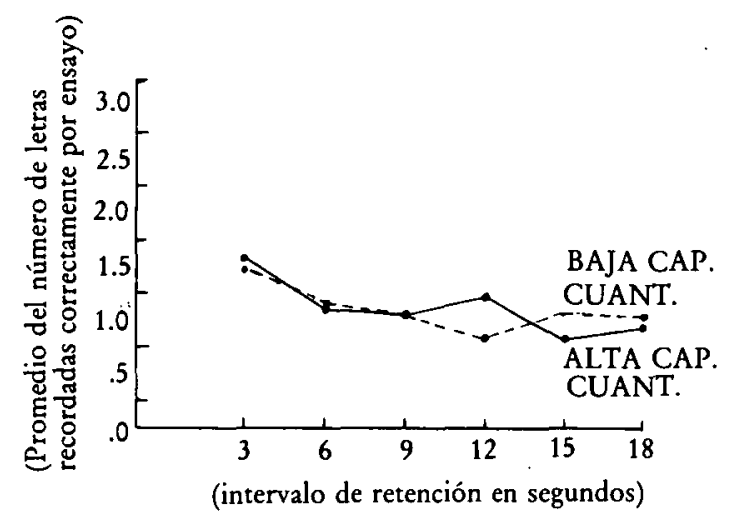

Tarea de Brown-Peterson con enmascaramiento mediante un ruido blanco durante la presentación de estimulos

bido a razones tangenciales, suponemos que el efecto se debe a la segunda. El recuerdo encontrado en un experimento de descarga de la IP estaba asociado con la capacidad verbal. También examinamos las puntuaciones de capacidad cuantitativa de los sujetos en este experimento, y no hallamos indicadores de posibles relaciones entre capacidad cuantitativa y descarga de la IP, o entre capacidad cuantitativa y aparición de inhibición en los ensayos. De esta forma, parece que los sujetos de alta capacidad cuantitativa son menos susceptibles a la distracción a la hora de consolidar información en la MCP, y no son má hábiles para distinguir entre los datos en los ensayos previos y concurrentes, lo que presumiblemente es la explicación para el efecto básico de la IP.

\section{Adquisición y recuperación desde la MLP.}

Hemos visto que la MLP, tal y como se entiende generalmente, se refiere más bien a lo que nosotros hemos denominado MMP. Vamos a realizar un estudio un tanto diferente que trate la cuestión de las diferencias individuales en la memoria de naturaleza más permanente.

Thomas Nelson realizó un estudio de pares asociados en el que se les pidió a los sujetos que aprendiesen 24 nombres, verbos o adjetivos emparejados con números. Se consideró aprendizaje, de acuerdo a un método modificado estudio-prueba, si se alcanzaba el criterio de un ensayo perfecto. Se puso a prueba la retención de los sujetos 5 semanas más tarde.

La Tabla V presenta las correlaciones entre los errores durante la adquisición, el número de asociaciones retenidas $\mathbf{5}$ semanas más tarde, y las composiciones WPC. El resultado respecto a los verbos es confuso, por lo que la discusión, de estos datos necesita más estudio. El resultado de interés hace referencia a los diferentes correlatos de adquisición y retención. $\mathrm{La}$ adquisición de una lista de pares asociados requiere utilizar la MCP y la MMP. La capacidad verbal, que como vimos estaba relacionada con la rapidez de codificación, fue el mejor predictor de la adquisición, para los grupos de nombres y adjetivos, y la predicción no aumentó significativamente al utilizar las puntuaciones en capacidad cuantitativa como segundo 
predictor. Exactamente, la relación opuesta fue el predictor de la retención 5 semanas más tarde. La capacidad cuantitativa fue el mejor predictor de la retención, y la capacidad verbal no sirvió como predictor asociado. Este patrón de correlaciones es consistente con las observaciones encontradas en el experimento de resistencia a la interferencia.

TABLA V

Correlaciones $y$ correlaciones parciales de las puntuaciones en capacidad verbal y cuantitativa con adquisición y retención

\begin{tabular}{|c|c|c|c|c|c|c|}
\hline \multirow[b]{2}{*}{$\begin{array}{c}\text { Subtest } \\
\text { psicométrico }\end{array}$} & \multicolumn{3}{|c|}{$\begin{array}{l}\text { Adquisición } \\
\text { (errores según criterio) }\end{array}$} & \multicolumn{3}{|c|}{$\begin{array}{l}\text { Retención } \\
\text { (número recordado) }\end{array}$} \\
\hline & $\begin{array}{c}\text { Grupo } \\
\text { nominal }\end{array}$ & $\begin{array}{c}\text { Grupo } \\
\text { de grupo }\end{array}$ & $\begin{array}{l}\text { Grupo } \\
\text { de adjet. }\end{array}$ & $\begin{array}{l}\text { Grupo } \\
\text { de adjet. }\end{array}$ & $\begin{array}{c}\text { Grupo } \\
\text { nominal }\end{array}$ & $\begin{array}{c}\text { Grupo } \\
\text { de grupo }\end{array}$ \\
\hline \multirow{3}{*}{$\begin{array}{l}\text { C. Verbal } \\
\text { C.V. (C.C.) } \\
\text { C.v. errores } \\
\text { de adquisición } \\
\text { C.V. (C.C } \\
\text { y errores) }\end{array}$} & $\begin{array}{l}-51 \\
-36\end{array}$ & $\begin{array}{l}-45 \\
-45\end{array}$ & $\begin{array}{l}-29 \\
-30\end{array}$ & $\begin{array}{l}30 \\
14\end{array}$ & $\begin{array}{l}15 \\
24\end{array}$ & $\begin{array}{l}21 \\
18\end{array}$ \\
\hline & & & & 27 & -22 & 21 \\
\hline & & & & 15 & $\infty$ & 18. \\
\hline \multirow{3}{*}{$\begin{array}{l}\text { C. Cuantitativa } \\
\text { (C.C.) } \\
\text { C.C. (C.V.) } \\
\text { C.C. (errores } \\
\text { de adquisición) } \\
\text { C.C. (C.V. } \\
\text { y errores) }\end{array}$} & $\begin{array}{l}-44 \\
-23\end{array}$ & $\begin{array}{r}-18 \\
15\end{array}$ & $\begin{array}{l}05 \\
08\end{array}$ & $\begin{array}{l}36 \\
24\end{array}$ & $\begin{array}{l}-15 \\
-08\end{array}$ & $\begin{array}{l}16 \\
35\end{array}$ \\
\hline & & & & 33 & -36 & 36 \\
\hline & & & & 24 & -29 & 35 \\
\hline
\end{tabular}

(Las correlaciones .34 y .46. son significativas a niveles .05 y .01 con 24 sujetos).

\section{Estudios correlacionales}

Hemos afirmado que los instrumentos de los psicólogos experimentales pueden iluminar los problemas de los psicómetras. El hecho de que se hayan utilizado los mismos sujetos en una serie de experimentos nos permite invertir el procedimiento, estudiando las correlaciones entre las medidas de diferentes tareas. El procedimiento necesario para llevar a cabo esta labor difiere de los análisis psicómetricos usuales de una bateria de tests, puesto que no todos los sujetos participaron en todos los experimentos; este problema se puede resolver aplicando los procedimientos usuales cuando se presentan valores perdidos.

La Tabla VI muestra la matriz de correlaciones de 15 variables. Esta matriz se sometió a un análisis factorial usando la técnica de componentes principales, y se rotaron ortogonalmente los factores resultantes buscando la estructura simpie, utilizando el criterio varimax de Kaiser (Harman, 1967). El criterio varimax sitúa los ejes mediante el análisis factorial en una orientación que tiende a maximizar las cargas factoriales altas y bajas en cada factor, haciendo más fácilmente interpretables los factores.

La Tabla VII presenta las cargas factoriales para cada test en los cinco primeros factores. El primer factor extraído dio cuenta del $25 \%$ de la varianza, el siguiente factor del $16 \%$, y los siguientes tres factores del $10 \%$ cada uno. 


\section{4}

TABLA VI

Correlación entre las medidas de las tareas

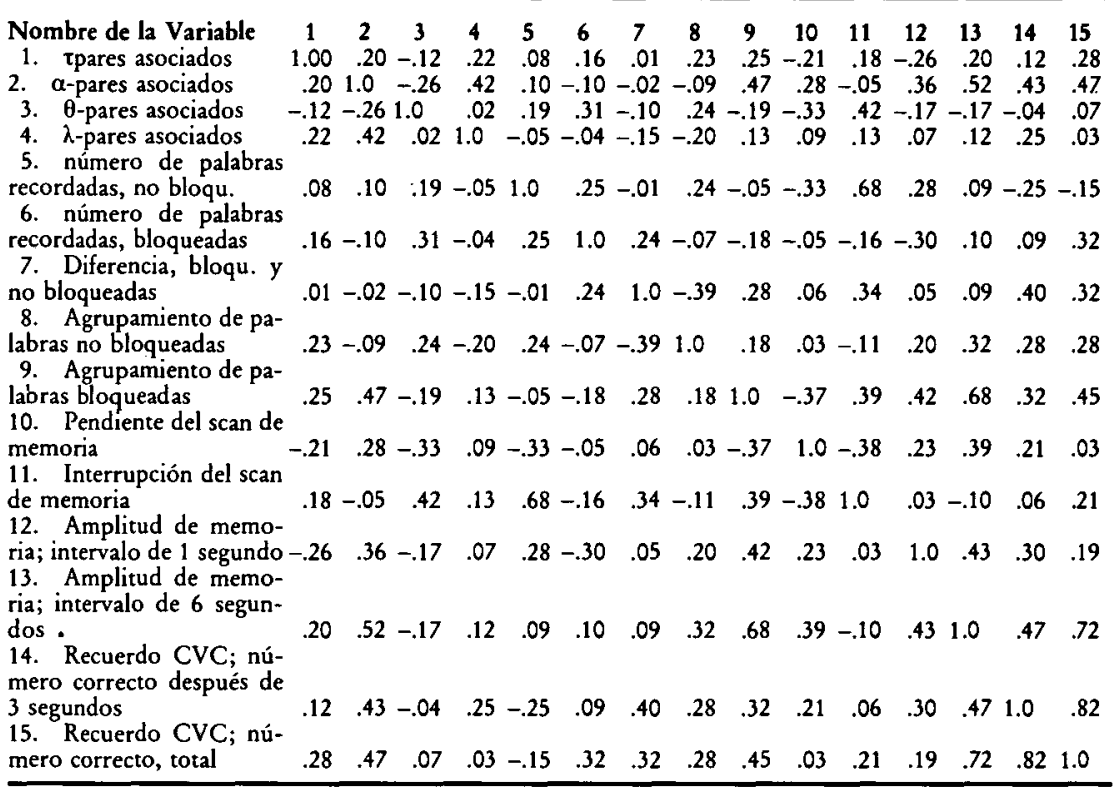

El Factor I, el mayor y estadísticamente más fiable, parece ser un factor generalizado de "eficacia de $\mathrm{MCP}$ ». Los tests con más carga en este factor, como amplitud de memoria en un bajo rango de presentación y recuerdo CVC, generalmente requiere el recuerdo de información menos significativa en breves períodos de tiempo. Los tests que tienen cargas intermedias, como el parámetro $\alpha$ de Atkinson y Shiffrin que mide la probabilidad de que un ítem acceda a MCP, o la amplitud de memoria en un rango rápido de presentación, implica no sólo el mantener la información, sino además otras capacidades, como la rapidez de codificación. Las medidas de la ejecución de MLP, como por ejemplo los parámetros $\theta$ y $\mathrm{r}$ del modelo de Atkinson y Shiffrin, son independientes del Factor I.

El significado del segundo factor es menos claro. Parece ser una medida de la capacidad para mantener material significativo durante un breve período de tiempo. El test definitorio es el número de palabras recordadas en una tarea de recuerdo libre de una lista no ordenada. El promedio de rapidez de recuerdo en la tarea de memoria de Sternberg tiene una carga apreciable en el Factor II. Sugerimos que el Factor II puede estar relacionado con la rapidez con que se puede establecer el significado cuando aparece en $\mathrm{MCP}$ un item sobreaprendido.

Los Factores III y IV parecen ser medidas específicas de la ejecución en la tarea de agrupamiento. El Factor IV, por ejemplo, es el equivalente factorial del resultado experimental que muestra que algunos sujetos cambian de estrategia de recuerdo cuando deben operar con listas bloqueadas o pseudoaleatorias.

El Factor $V$ se define por una gran carga para la amplitud del buffer de MCP, tal y como lo hemos medido por la tarea de pares asociados, y por 
TABla VII

Cargas de los factores rotados

\begin{tabular}{|c|c|c|c|c|c|}
\hline Nombre de la Variable & Factor I & Factor II & Factor III & Factor IV & Factov $\mathrm{V}$ \\
\hline $\begin{array}{l}\text { 1. } \text { t-pares asociados } \\
\text { 2. a-pares asociados } \\
\text { 3. } \theta \text {-pares asociados } \\
\text { 4. } \lambda \text {-pares asociados } \\
\text { 5. Número de palabras } \\
\text { recordadas, no bloqu. } \\
\text { 6. Número de palabras } \\
\text { recordadas, bloqueadas } \\
\text { 7. Diferencia, bloqu. y } \\
\text { no bloqueadas } \\
\text { 8. Agrupamiento de pa- } \\
\text { labras no bloqueadas } \\
\text { 9. Agrupamiento de pa- } \\
\text { labras bloqueadas } \\
\text { 10. Pendiente del scan de } \\
\text { memoria } \\
11 . \quad \text { Interrupción del scan } \\
\text { de memoria } \\
\text { 12. Amplitud de memo- } \\
\text { ria; intervalo de } 1 \text { segundo } \\
\text { 13. Amplitud de memo- } \\
\text { ria; intervalo de } 6 \text { segun- } \\
\text { dos } \\
\text { 14. Recuerdo CVC; nú- } \\
\text { mero correcto después de } \\
3 \text { segundos } \\
\text { 15. Recuerdo CVC; nú- } \\
\text { mero correcto, total }\end{array}$ & $\begin{array}{l}.21 \\
.48 \\
.01 \\
.06 \\
.10 \\
.17 \\
.36\end{array}$ & $\begin{array}{r}-.20 \\
.58 \\
.44\end{array}$ & $\begin{array}{r}-.09 \\
.38 \\
-.09\end{array}$ & $\begin{array}{r}-.05 \\
-.54 \\
.22 \\
-.25 \\
-.45\end{array}$ & $\begin{array}{r}.11 \\
-.01 \\
.07 \\
.41\end{array}$ \\
\hline
\end{tabular}

una carga negativa en relación a la pendiente de la tarea de Sternberg. Ambas medidas reflejan la rapidez de codificación. Si un sujeto puede producir una serie de códigos compactos rápidamente, bajo las condiciones de la tarea de pares asociados, obtendrá un valor alto de $r$. De igual manera, una pendiente baja en la tarea de Sternberg representa el acceso rápido a MCP. El Factor $V$ nos trae a la mente la ejecución del mnemonista VP (Hunt y Love, 1972a, 1972b). Una de las diferencias entre VP y otros sujetos igualmente inteligentes que no tenían memorias excepcionales, es la rapidez con la que es capaz de producir códigos semánticos para cualquier material estimular. En otras palabras, la ejecución de VP quedaría definida por el Factor V.

Para cerrar la discusión de estos resultados, diremos una palabra de precaución. El Factor I es sustancial y posiblemente fiable. Representa una validación interesante del concepto de MCP fuera de la tradición de la psicología experimental. Los otros factores sólo pueden considerarse sugerentes. Hay que hacer notar, no obstante, que hay una pequeña diferencia entre los factores. El Factor $V$ es tan amplio como el Factor III, y no terriblemente más pequeño que el Factor î̃, por lo que consideramos que sus fiabilidades deben considerarse equivalentes.

\section{DISCUSIÓN}

La pregunta lógica es qué significa todo esto. La respuesta dependerá de la persona que responda la pregunta. Estos resultados tienen diferentes 


\section{6}

significados para el psicólogo generalmente interesado en las diferencias individuales, para el experimentalista que estudia la cognición, y para el psicómetra que desea evaluar el funcionamiento mental.

El psicólogo general habrá observado que presentamos resultados significativos, pero no mostramos correlaciones elevadas. Por el contrario, nuestros estudios pueden ser criticables por el hecho de que hemos presentado un amplio número de correlaciones moderadas, y no hemos analizado ninguna relación con mucho detalle. Nuestros datos, por tanto, quizá sean más sugestivos que concluyentes. Uno de nuestros puntos de partida, no obstante, fue que las correlaciones positivas bajas tenían interés. Aunque parezca razonable esperar a priori que el estudio de las diferencias individuales en el ámbito cognitivo podría localizar las mismas variables críticas subyacentes a la ejecución humana, tal y como lo revelaría la aproximación experimental a la cognición, en realidad, no ha sucedido así. Los psicómetras y la psicología cognitiva parecen adoptar una información similar sobre el hombre, pero no duplicada. Al menos, no vemos otra forma de dar cuenta del patrón de resultados. Por el contrario, creemos que es un soporte de nuestra proposición básica. El resultado de relaciones consistentes, aunque moderadas, entre las variables de diferencias individuales y la ejecución experimentalmente manipulada refuerza nuestra posición de que estamos en el momento adecuado para comenzar a desarrollar tests teóricamente orientados, y que es el momento de considerar las diferencias entre la gente en nuestros modelos de la cognición.

Nuestros datos sugieren un cambio al psicólogo experimental en dos niveles. Empíricamente, hemos mostrado que las diferencias individuales interactúan sistemáticamente con los efectos del tratamiento en una serie de los paradigmas más populares de la psicología cognitiva moderna. Este es un estatuto ateórico; para descreerlo se debe uno enfrentar a nuestros datos antes que a nuestra interpretación de los estudios. Absolutamente sin teoría, la existencia de una interacción entre los efectos del tratamiento y las características del sujeto supone un problema para el experimentalista. La lógica de la mayor parte de los estudios experimentales asumen que el "término error" representa el error de medida y que se distribuye aleatoriamente a través de las observaciones. Nuestros resultados ponen en duda este supuesto. El cambio no hace referencia a la legitimidad de la estadística, puesto que el análisis estadístico que utiliza el modelo denominado «efectos fijos" es tan apropiado como la asignación al azar de los sujetos a las condiciones de tratamiento. El cambio se dirige a las generalizaciones que esperamos hacer a partir de un estudio experimental. La inmensa mayoría de experimentos ser han realizado utilizando sujetos de la propia institución del experimentador. Nosotros hemos mostrado que dentro de la población de estudiantes de una determinada universidad se presentan interacciones sistemáticas entre las diferencias individuales y el tratamiento. Esperamos encontrar interacciones más amplias al estudiar poblaciones de diferentes instituciones. Las inferencias realizadas a partir de estudios con universitarios deben tener ciertas reservas. Los psicólogos han sido conscientes, y han ignorado, esta realidad. La asunción implícita ha sido que mientras que los niveles de ejecución pueden variar en diferentes poblaciones, se podrían encontrar las mismas relaciones entre las condiciones de ejecución y tratamiento. Nuestros datos no apoyan esta idea. Parece impro- 
bable que un modelo general de la cognición se pueda basar en la ejecución de los sujetos de un ámbito restringido.

Los experimentalistas interesados en la cognición podrian considerar nuestros resultados en la construcción de modelos formales del pensamiento. La interpretación de los datos dependerá, no obstante, de cómo un determinado teórico contemple la situación experimental estudiada por nosotros. Por ejemplo, una persona que rechace las asunciones del MMD probablemente no aceptará nuestra discusión de la tarea de pares asociados. Nuestras interpretaciones de los estudios nos llevan a concluir, tentativamente, que existe una relación entre la rapidez de los procesos de MCP y la capacidad verbal, y entre la resistencia a la interferencia y la capacidad cuantitativa. En un nivel más general, hemos demostrado relaciones entre factores psicométricamente definidos de capacidad mental y los'parámetros de un modelo de la cognición del procesamiento de la información. Esta es la faceta más importante de nuestro estudio. Los experimentos que hemos realizado son relativamente toscos. Nos hemos centrado en parámetros globales, hemos usado sujetos de rangos restringidos de capacidad mental, y hemos utilizado un pequeño número de sujetos. De todas formas, hemos obtenido resultados que muestran una cierta coherencia. No obstante, hay otros aspectos del modelo del procesamiento de la información, y otros factores que requieren exploración.

Nuestros resultados también enfatizan un punto importante que ha sido generalmente dejado de lado por los experimentalistas y los psicómetras. Resultados equivalentes pueden obtenerse por diferentes procesos. En nuestro estudio del agrupamineto, los sujetos de alta y baja capacidad verbal recordaron casi exactamente el mismo número de ítems a partir de las listas no bloqueadas (o pseudoaleatorizadas). Para hacer esto, los sujetos de baja capacidad verbal, agrupan semánticamente, mientras los sujetos de alta capacidad verbal no utilizan esta estrategia.

En otro estudio (del que informaremos en otra ocasión) sujetos de alta y baja capacidad verbal participaron en una tarea de memoria de reconocimiento en la que los estímulos fueron nombres escritos o caras de niños. Los sujetos de alta capacidad verbal adoptaban consistentemente una estrategia nominal (se presentó una correlación sustancial entre su ejecución en el reconocimiento de nombres y rostros). Los sujetos de baja capacidad verbal tendían a centrarse en aspectos perceptuales (su ejecución en reconocimiento de rostros no correlacionó con la ejecución en la tarea verbal). Resultados similares se han encontrado en una investigación en la que sujetos de alta y baja capacidad verbal se enfrentaban a una tarea de reconocimiento de dibujos - Mooney Closure Tests; test que mide la capacidad de los sujetos para formar una Gestalt; y se ha utilizado para evaluar el daño cerbral asociado a la pérdida de la capacidad gestáltica- (Landsdell, 1968). Cuando los sujetos de alta capacidad verbal cumplimentan el test, lo transforman en una tarea de etiquetado, mientras que los sujetos de baja capacidad verbal tratan el material visual directamente.

Encontramos un ejemplo aún más significativo de diferncias cualitativas producidas al mismo nivel de ejecución, cuando consideramos el caso de los dos mnemonistas. El sujeto "S" de Luria (1968), y el sujeto "VP» estudiado recientemente por Hunt y Love (1972a, 1972b). Está claro que ambos sujetos ejecutan excepcionalmente las tareas experimentales clásicas 
de los psicólogos cognitivos interesados en la memoria. El cómo resuelven las tareas es algo absolutamente diferente. De acuerdo al informe de Luria, «S» era un mnemonista de imágenes, de forma que se basaba fundamentalmente en los trazos de memoria almacenados a modo de imágenes sensoriales. Por otro lado, "VP» se basaba en etiquetas verbales y en códigos semánticos. Es particularmente interesante hacer notar que VP hacía esto debido a que, en los términos de nuestra muestra, tenía altas puntuaciones en capacidad verbal y capacidad cuantitativa. Su ejecución indicaba que era extremadamente rápido en la codificación estimular, y que era virtualmente inmune a la interferencia retroactiva. (iRecordó perfectamente en varias ocasiones 150 ensayos en la tarea de pares asociados!). VP también era un maestro del ajedrez, lo que indicaba su competencia para el razonamiento analítico. No existen datos formales disponibles sobre la inteligencia de $\mathrm{S}$, pero la descripción clínica de Luria sugiere que no era excepcionalmente inteligente, especialmente en razonamiento cuantitativo, o en abstracción lingüistica. De hecho, resolvía problemas de aritmética a través de su visualización. Por tanto, podemos imaginar dos tipos de grupos de individuos, uno de ellos compuesto de "VPs» y el otro de «Ss», dando lugar a resultados homogéneos en una serie de tareas de memoria, ejecutando las tareas según estrategias ampliamente diferentes.

Los únicos teóricos cognitivos que se han dado por aludidos han sido aquellos que se dedican a desarrollar modelos de simulación por ordenador; estos teóricos suelen proponer distintos modelos para cada individuo. Es muy posible que este tipo de trabajos no permitan realizar una descripción económica. Nosotros nos situamos en un término medio, entre el modelo para el hombre universal y el modelo para cada individuo. Y aquí es donde puede ayudar el psicómetra. ¿Cuáles son las implicaciones de nuestros resultados para esta área de la psicología?

En nuestros estudios iniciales, hemos proporcionado al psicómetra un pequeño vistazo de una nueva base teórica para la evaluación intelectual. El cambio supone comenzar a incorporar esto en las relaciones empíricamente establecidas que forman la base de la práctica psicométrica. Puede ser una tarea de múltiples facetas, que implicarían, cuando menos, cuatro conjuntos de relaciones: entre las medidas psicométricas existentes, entre medidas procesuales o parámetros derivados del modelo cognitivo, entre estas medidas psicométricas y procesuales, y entre las evaluaciones psicométricas y la subsecuente ejecución en contextos socialmente significativos.

Permitásenos considerar en primer lugar, tentativamente, el último de estos conjuntos de relaciones. Está bien establecido que la capacidad verbal es un predictor útil del éxito en determinadas vocaciones. Lo que nosotros sugerimos es que la capacidad verbal está relacionada con la rapidez del preocesamiento de la información en MCP. ¿Podrían los psicómetras identificar situaciones en las que sean consonantes las dos relaciones, en las que la rapidez del procesamiento en MCP sea predictivo del éxito en un trabajo? Esto parece razonable, y por nuestra parte creemos que estas nuevas relaciones predictivas tendrán implicaciones más significativas que las relaciones psicométricas actuales, incluso cuando la nueva relación predictiva no sea tan poderosa como la antigua. Debido a la base empírica ateórica de un constructo como la capacidad verbal que sólo produce medidas re- 
lativas, tenemos disponibles algunos indicadores que sugieren cómo (o si) la capacidad verbal se puede modificar en los individuos. Como resultado, la tentación de tratar a las personas es más grande. Un predictor teóricamente basado, debido a la teoría, es más susceptible de implicaciones respecto a su modificabilidad. El entrenamiento en la eficiencia de procesamiento de la MCP, por ejemplo, parece más directamente abordable que el intentar incrementar la capacidad verbal. Nos parece probable que un nuevo conjunto de medidas sobre la inteligencia teóricamente basadas transformará gran parte de las predicciones psicométricas de postulados estáticos sobre la probabilidad de éxito, en postulados dinámicos sobre qué deberíamos hacer para incrementar la probabilidad de éxito. Estos cambios requieren más mediciones, de las ejecuciones relacionadas con el modelo cognitivo, de las que nosotros hemos realizado.

En un futuro inmediato, por tanto, el cambio en la psicometría consistirá en desarrollar instrumentos analíticos multivariados para tratar de medir multidimensionalmente el funcionamiento cognitivo basado en un modelo. El modelo, por supuesto, proporciona una guía respecto a lo que teóricamente debería medirse, pero en la medida en que no sea sensible a los patrones de diferencias individuales, estaremos tratando con algo distinto a lo que pretendemos medir. Sugerimos que una vez que se haya realizado una evaluación más extensa, los parámetros del modelo serán más susceptibles de factorializarse. Por ejemplo, las medidas de rapidez de codificación y el tiempo emnpleado, serán un reflejo de la cognición subyacente diferente para los diferentes individuos, de la misma forma a como computa el ordenador en intervalos temporales diferentes. Si esto es cierto, los parámetros afectados por el ciclo temporal cognitivo deplegarán una determinada estructura factorial. Además, a parte de consideraciones teóricas, sospechamos que aparecerán constricciones culturales (educacionales) muy fuertes en la selección de los procesos de control, que, para cualquier razón práctica, no se tendrán por qué evaluar para todo parámetro del modelo.

No obstante, un problema importante muy relacionado con la determinación de una adecuada dimensionalización para la evaluación cognitiva, es la de identificar los tipos cognitivos. De todas formas, hemos sugerido que el psicómetra puede ayudar al establecimiento de un ámbito intermedio entre el modelo cognitivo universal, y el modelo idiosincrásico para cada individuo. Aunque sólo sea, por el momento, un deseo, existen ciertas constricciones lógicas, fisiológicas y culturales contra la ocurrencia de determinadas combinaciones de valores paramétricos. Qué patrón ocurre, con qué frecuencia, y bajo qué circunstancias, son preguntas que, además de ser inherentemente interesantes para el psicómetra multivariado, tiene implicaciones para el experimentalista o teórico cognitivo. No obstante, creemos que el desarrollo positivo de esta área dependerá del ciclo recursivo entre el trabajo psicométrico y experimental. Tal y como el modelo cognitivo sugiere la obtención de determinadas medidas, el análisis psicométrico de las relaciones entre estas medidas sugerirá, en cambio, modificaciones del modelo, de lo que se derivarán nuevas medidas, nuevos análisis, etc.

Permitásenos considerar ahora el tipo de medidas a realizar. Las medidas que hemos realizado sobre la ejecución cognitiva se obtuvieron repli- 
cando experimentos clásicos. El someter a los sujetos a paradigmas que producen un parámetro después de una hora de trabajo es muy práctico, no obstante. Un cambio final del psicómetra es el desarrollo de tests fiables de los parámetros del modelo de razonable longitud. Estas nuevas medidas teóricamente basadas tendrán escaso parecido a los tests de papel y lápiz, de formatos multielección que utilizan extensamente los tests psicométricos actuales. Se debe dar más importancia a las medidas de la latencia de respuesta, al tiempo de exposición del material del test, y al registro y puntuación de respuestas abiertas en oposición a las respuestas de elección.

Afortunadamente, esperamos una tecnología más económica, evaluando mediante ordenador, a medida que se confeccionen nuevas medidas. Estamos encantados de hacer notar que un número cada vez más alto de psicómetras están trabajando en problemas relacionados con la nueva tecnología.

\section{CONCLUSIÓN}

Hemos presentado un argumento teórico, y hemos proporcionado datos para apoyar una nueva conceptualización de la inteligencia. El fundamento de nuestro argumento es que la inteligencia puede determinarse mediante medidas absolutas de los aspectos de la capacidad del procesamiento de la información de una persona, mejor que mediante medidas de su ejecución relativa respecto a la muestra poblacional. Si reemplazamos la definición relativista de la inteligencia por una definición en los términos del procesamiento de la información, forzaremos un cambio en la forma en que concibamos y utilicemos las medidas de inteligencia. Esto puede suponer ventajas y desventajas. Desde el punto de vista científico pisaremos terreno más firme cuando relacionemos las diferencias individuales con un modelo general de la cognición. Esto no es sólo lógicamente deseable, sino que además tiene importantes consecuencias respecto a la continuación de las controversias sobre la inteligencia. Por ejemplo, la polémica natura-nutura se transformará en la polémica respecto a qué parámetros son entrenables y cuáles no lo son -i.e. cuáles son heredables-. A nivel práctico, los tests de inteligencia medirán qué puede hacer un hombre, antes que qué puede hacer en relación a otros individuos. Tal cambio en los tests puede conllevar algunas implicaciones embarazosas. La selección de personal, por ejemplo, ha hecho un uso efectivo del modelo relativista de las capacidades. El nuevo punto de vista sobre la inteligencia promoverá la creación de instrumentos de medida que permitan diagnosticar, en el sentido de que permitirá conocer cómo se deberían ajustar la institución y el individuo, en lugar de informarnos simplemente de qué gente se ajusta al perfil que exige una determinada institución. Un mayor desarrollo de este tipo de tests es, por supuesto, una proyección al futuro. Antes de llegar a ese punto debemos de cumplir con una serie de investigaciones, dentro de la cual la presente investigación es sólo un paso. Además, deberemos desarrollar una tecnología de tests que haga uso de las técnicas de la psicología experimental. Creemos que ésta tarea es realizable. El cambio científico está frente a nosotros. Una vez decidamos qué tenemos que medir, encontraremos la manera de hacerlo. 
Referencias

AtKINSON, R.; BRELSFORD, J. W., y SHIFFRIN, R. M. (1967). Multiprocess models for memory with applications to a continuous presentation task. Journal of Mathematical psycho$\log y, 4,277-300$.

AtKinson, R. C., y Shiffrin, R. M. (1968). Human memory: a proposed system and its control processes. En K. W. Spence y J. T. Spence (comps.): The psycology of learning and motivation: advances in research and theory. Vol. 2. Nueva York: Academic Press.

Atkinson, R., y SHIFFrin, R. M. (1971). The control of short term memory. Scientific Ame- rican, 225, 82-90.

BINET, A. (1890). La courrence des états psychologiques. Revue de la France et l'Etranger, $24,138-155$.

BOUSFIELD, W. A. (1953). The ocurrence of clustering in the recall of randomly arranged associates. Journal of General Psychology, 49, 229-240.

CATTELL, R. B. (1971). Abilities: their structure, growth and action. Boston: Houghlin.

COfER, C. N.; BRUCE, D. R., y ReICHER, G. M. (1966). Clustering in free recall as a function of certain methodological variations. Journal of Experimental Psychology, 71, 858-866.

ESTES, W. K. (1970). Learning theory and mental development. Nueva York: Academic Press.

GARNATZ, D., y HuNT, E. (1973). Eyeball parameter estimation with a computer, IEE transactions on systems, man and cybernetics. SMC-3, 1, 45-51.

GazzanigA, S. M. (1969). The bisected brain. Nueva York: Academic Press.

GESCHWIND, N. (1970). The organization of language in the brain. Science, 170, 940-944.

GUILFORD, J. P. (1967). The nature of buman intelligence. Nueva York: McGraw-Hill.

HARMAN, H. (1967). Modern factor analysis. Chicago: University of Chicago Press.

HunT, E. (1971). What kind of computer in man? Cognitive Psychology, 2, 57-98.

Hunt, E. (1973). The memory we must have. En R. Schanck, y K. Colby (comps.): Computer simulation of information processes in man. San Francisco: Freeman.

HunT, E., y Love, T. (1972a). How good can memory be? En A. Melton, y E. Martin (comps.): Coding and memory. Nueva York: Academic Press.

Hunt, E., y Love, T. (1972b). The second mnemonist. Paper presented at the meeting of the American Psychological Association, Honolulu.

JENSEN, A. R. (1970). Hierarchical theories of mental ability. En W. B. Dockrell (comp.): On intelligence. Londres: Methuen.

LANDSDELL, H. (1968). Effect of temporal lobe deficits on two lateralized defects. Psysiology of Behavior, 3, 271-273.

LASHLEY, K. S. (1951). The problem of serial order in behavior. En L. A. Jeffress (comp.): Cerebral mechanisms in behavior. Nueva York: Wiley.

LENNEBERG, E. H. (1967). The biological foundations of language. Nueva York: Wiley.

LOFTUS, G. R. (1971). Comparison of recognition and recall in a contonuous memory task. Journal of Experimental Psychology, 91, 220-226.

LURIA, A. (1968). The mind of a mnemonist. Nueva York: Basic Books.

MEYER, D. E. (1970). On the representation and retrieval of stored semantic information. Cognitive Psychology, 1, 201-214.

Milner, B. (1970). Memory and the medial temporal regions of the brain. En K. Pribram, y D. E. Broadbent (comps.): Biology of memory. Nueva York: Academic Press.

Peterson, L. R., y PETERSON, M. J. (1959). Short-term retention of individual items. Journal of experimental psychology, 58, 193-198.

Posner, M. I., y BOIES, S. (1971). Componentes of attention. Psychological Review, 78, 391-408.

PUFF, C. R. (1966). Clustering as a function of sequential organization of stimuls word lists. Journal of verbal learning and vergal behavior, 5; 503-506.

Quillian, M. R. (1968). Semantic memory. En M. Minsky (comp.): Semantic information processing. Cambridge, Mass: MIT Press.

ReITAN, R. (1964). Psychological deficits resulting for cerebral lesions in man. En J. Warren, y K. Akert (comps.): The frontal granular cortex and behavior. Nueva York: McGrawHill.

RESTLE, F. A. (1970). Speed of adding and comparing numbers. Journal of experimenal psycho$\log y, 83,274-278$.

Rumelhart, D. E.; Lindsay, P. H., y Norman, D. A. (1972). A process model for long term memory. En E. Tulving, y W. Donaldson (comps.): Organization and memory. Nueva York: Academic Press.

SCHANCK, R. (1969). A conceptual dependency representation for a computer oriented semantics. A.I. Memo 75, Stanford University Department of Computer Science.

Shepard, R. N., y METzler, J. (1971). Mental rotation of three dimensional objects. Science, $171,701-703$. 